\title{
«EL DELINCUENTE HONRADO» DE JOVELLANOS TRADUCIDO AL ITALIANO POR EL JESUITA ANTONIO GARCÍA (1807)
}

\author{
Belén TEJERINA \\ Universidad de Viterbo
}

\begin{abstract}
Resumen
El objeto de este artículo es el análisis detallado de la primera traducción italiana publicada de El delincuente honrado de Jovellanos, que salió a la luz en Venecia en 1807, siendo su autor el jesuita abulense Antonio García López, del que se ofrece un perfil bio-bibliográfico. A modo de introducción se traza un panorama de las traducciones italianas de esta obra de Jovellanos, algunas de las cuales son poco conocidas.
\end{abstract}

\begin{abstract}
The object of this article is the detailed analysis of the first published Italian translation of El delincuente honrado by Jovellanos, that come to light in Venice in 1807, being its author the Jesuit born in Avila Antonio García López, of whom is offered a bio-bibliographical outline. As an introduction it offers an overall view of the Italian translations of this Jovellanos' work, some of them very little known.
\end{abstract}

Como es sabido, Gaspar Melchor de Jovellanos (1744-1811) en 1773, a la sazón Alcalde del Crimen de la Real Audiencia de Sevilla, escribe El delincuente honrado ${ }^{1}$, en donde refleja sus experiencias como magistrado. El objeto de este drama según el escritor es «descubrir la dureza de las leyes, que sin distinción de provocado y provocante castigan a los duelistas con pena capital». La obra se estrena en 1774, pero Jovellanos no precisa si es en el Teatro de San Ildefonso o en el de Aranjuez; en este año el escritor asturiano había ascendido a Oidor de la misma Real Audiencia ${ }^{2}$.

1. Jovellanos precedentemente (1769) había escrito una tragedia El Pelayo que fue publicada en 1792 con el título de Munuza. Munuza. Tegedia en cinco actos, s.1., s.i., s.a. [1792].

2. Es exhaustiva la bibliografía sobre Jovellanos y El delincuente honrado por lo que nos limitamos a citar la introducción de J. Caso González, G. M. de Jovellanos, Obras en prosa, Madrid, Castalia, pp. 7-58; Jean Sarrailh, «A propos du Delincuente honrado de Jovellanos», en Mélanges d'Etudes portugaises of- 
A raíz del estreno El delincuente honrado se representó en varios teatros de la península; de hecho, circulaba manuscrito con innumerables variantes y tan desfigurado que hasta lo habían puesto en verso. En 1787, cuando Jovellanos había sido nombrado Alcalde de Casa y Corte, y no había tenido más remedio que cambiar su residencia de Sevilla a Madrid, decide publicar una edición bajo el pseudónimo de Toribio Suárez de Langreo ${ }^{3}$. Precisa en la Advertencia del editor que aquí aparece la comedia «no sólo corregida, sino también completa, y tal qual ha sảlido de las manos de su autor» (p. VI), por lo que esta edición puede considerarse la príncipe ${ }^{4}$. El delincuente se representó en Madrid en el teatro del Príncipe del 8 al 15 de agosto de 1791, y en 1793 «corregida y arreglada», según la edición de Suárez de Langreo; no hace falta decir que mereció una reseña muy positiva de El memorial literario $^{5}$ :

«por una bien conducida trama y contextura, episodios propios y bien unidos, y situaciones escelentes por sus contrastes, mutación de fortuna, reconocimiento etc. crece el interés de escena en escena, y de acto en acto, sin decaer un punto de lo propuesto».

Según cuenta Jovellanos en la Advertencia (p. III) de la edición príncipe, en 1777 este drama se tradujo al francés y se sabe que el traductor fue Ange d'Eymar, Abad de Valcrétien y la puso el título de Le coupable vertueux; en 1778 se trabajaba en Sevilla en la traducción alemana y en 1779 estaba traducido incluso al inglés ${ }^{6}$.

El que nuestro escritor, quizá por motivos profesionales, no haya querido imprimir su nombre en el frontispicio de la comedia y ni siquiera cite en la Advertencia los nombres de los traductores, ha dado pie a que los críticos hayan encontrado muchas dificultades a la hora de identificar las traducciones, incluso, como veremos, en Italia, pues en algún caso no aparece el nombre de Jovellanos.

El objetivo de este trabajo es examinar la traducción italiana de El delincuente honrado que realizó en 1807 el jesuita Antonio García López, pero antes queremos trazar un panorama de las traducciones y adaptaciones italianas que se han realizado de la comedia española. A las dos traducciones que se conocen hasta ahora hay que añadir otras tres, desconocidas para la crítica, que hemos logrado localizar, aparecidas a lo largo del Siglo XIX: 1816, 1844 y 1848 . De todas estas traducciones Eduardo Toda y Güel ${ }^{7}$ en su Bibliografía sólo señala la de Antonio García.

ferts à $M$. Georges Le Gentil, Chartres, 1949, pp. 337-351; John H. R. Poit, «Jovellanos, El delincuente honrado», en Romantic Review, L (1959), pp. 170-190; José Caso González, «El delincuente honrado, drama sentimental», en Archivum, XIV (1964), pp. 103-133; L. McClelland, Spanish Drama of Pathos 1750-1808, II, Liverpool, University Press, 1970, pp. 397-507; Piero Menarini, «Tre contemporanei e il duello: Jovellanos, Iriarte, Montengón», en Spicilegio Moderno, $n^{\circ} 2$ (1973), pp. 53-79; John C. Dowling, «La sincronía de El delincuente honrado de Jovellanos y las Noches lúgubres de Cadalso», en Nueva Revista de Filología Hispánica, XXXIII (1984), pp. 218-223. Es interesante leer F. Aguilar Piñal, La biblioteca de Jovellanos (1778), Madrid, CSIC, 1984.

3. El Delinquente honrado, Comedia en prosa. Publícala D. Toribio Suárez de Langreo, Madrid, Viuda de Ibarra, Hijos y Compañía, 1787.

4. Sobre las ediciones de El delincuente cfr. P. Menarini, Una commedia «politica» dell'llluminismo: El Delincuente honrado di Jovellanos, en M. Fabbri, P. Garelli, P. Menarini, Finalità ideologiche e problematica letteraria in Salazar, Iriarte, Jovellanos, Pisa, Editrice Libreria Goliardica, 1974, pp. 91-168.

5. Cfr. Ada M. Coe, Catálogo Bibliográfico y Crítico de las comedias anunciadas en los periódicos de Madrid desde 1661 hasta 1819, Baltimore, The Johns Hopkins Press, 1935, p. 62.

6. Cfr. P. Menarini, Una commedia «politica» dell'Illuminismo, op. cit., p. 93.

7. E. Toda y Güel, Bibliografia Espanyola d'Itàlia, II, Castell de Sant Miquel d'Escornalbou, Vidal-Güell, 1928, pp. 147, 372-373. El Catalogo dei libri italiani dell'ottocento (1801-1900) (Clio), Milano, Editrice Bibliografica, 1991, bajo Jovellanos solo registra la traducción de García y la de Gómez de Terán. 
La primera traducción italiana de El delincuente honrado que conocemos actualmente, la señaló Joseph G. Fucilla hace varios años ${ }^{8}$; su autor es el jesuita español residente en Bolonia, Francisco Javier Peirolón (o Peyrolón) (1745-1791) y lleva el título: Il Torquato o sia l'onorato delinquente ${ }^{\vartheta}$. Para Fucilla, esta versión italiana «es un ejemplo admirable de traducción literal que conserva muy bien el sabor y el espíritu de la obra original». El jesuita precisa en la Avvertenza: «Il traduttore di questa tragedia urbana, che ha fatte quelle mutazioni convenienti all'indole del teatro italiano, non si è scostato dall'originale nel tradurre il Tu nelle scene famigliari, ma se nelle scene fra D. Torquato et Anselmo, o in quelle fra D. Simone e D. Torquato questa rassembrasse tropo soverchia famigliarità può sostituirse dal copista il Voi» ${ }^{10}$. Piero Menarini " es de la opinión que Peirolón en su traducción debió utilizar la edición de Gibért y Tutó ${ }^{12}$ y que fue realizada entre 1782 y 1791, ya que Peirolón murió el 26 de agosto de 1791. Este texto, que merecería la pena estudiar, se conserva todavía manuscrito en le Biblioteca del Archiginnasio de Bolonia ${ }^{13}$.

Francisco Javier Peirolón ${ }^{14}$ había nacido en Teruel el 3 de octubre de 1745, estudió en el Colegio de Segorbe, provincia de Aragón; entró en el Noviciado el 10 de julio de 1761 y el 1 de mayo de 1767 se embarcó en Salou en la Saetía «San Juan». En 1771 residía en Ferrara en donde el último trimestre de 1773 recibió 375 reales por su pensión ${ }^{15}$. De su producción literaria ${ }^{16}$ sabemos que escribió en italiano Jonatas $y$ Esther, y en español, una tragedia sagrada: San Adriano Mártir; tradujo en verso al español muchos epigramas de Marcial y compuso varias poesías líricas. Uno de sus poemas aparece en la colección de poesías que publicó el Colegio de San Clemente de Bolonia para celebrar el nacimiento de los Infantes gemelos Carlos y Felipe de Borbón (1738-1784), hijos de Carlos IV y de María Luisa de Parma ${ }^{17}$.

En 1807 aparecía en Venecia la traducción del abulense Antonio García López: Il Reo per onore ${ }^{18}$, que, como acabamos de decir, vamos a analizar en este trabajo; la

8. J. G. Fucilla, Relaciones hispanoitalianas, Madrid, CSIC, 1953 (Anejo LIX de la Revista de Filología Moderna), pp. 200-201.

9. Il Torquato o sia l'Onorato Delinquente. Tragedia Urbana di lieto fine. Tradotta dall'Idioma Spagnuolo dall'Abb. D. Francesco Saverio Peirolón.

10. Citado por J. G. Fucilla, Relaciones, op. cit, p. 200.

11. P. Menarini, Una commedia «politica» dell'llluminismo, op. cit., p. 94.

12. Tragi-comedia. En prosa. El Delinquente honrado. Caso sucedido en la Ciudad de Segovia en el año de 1738, Barcelona por Carlos Gibért y Tutó, s. a.

13. Bolonia, Biblioteca del Archiginnasio M.A. 432.

14. Carlos Sommervogel, Agustin et Aloys De Baker, Auguste. Carayon, Pierre Bliard, Ernest M. Rivière, Bibliothèque de la Compagnie de Jésus, VI, Bruxelles, 1895, p. 438.

15. A.G.S., Inventario 27, Dirección General del Tesoro, legajo 1. Estos datos me han sido facilitados por el colega y amigo Enrique Giménez.

16. Cfr. M. Luengo, Colección de Papeles Varios, T. XXV, p. 260

17. Poesie varie pubblicate dall'Almo Real Collegio di S. Clemente di Spagna in occasione del felice avvenimento della nascita dei Reali Infanti D. Carlo e D. Filippo di Borbón, Bologna, Stamperia della Volpe, 1783; la poesía de Peirolón está en la p. VII. Las otras poesías que aparecen son de Pedro Cordón (pp. III-IV); Lasala (p. VIII); Bartolome Pou (pp. IX-X, XI); y Tomás Serrano (p. XII). Cfr. J. E. de Uriarte, Catálogo razonado de obras anónimas y seudónimas pertenecientes a la antigua Asistencia Española, IV, Madrid, Sucesores de Rivadeneyra, 1914, p. 103.

18. Il Reo per onore ossia Il delinquente onorato, commedia urbana in cinque atti tradotta dal castigliano dal Signor abbate D. Antonio Garzia, Venezia, Andrea Santini, 1807. 
traducción está dedicada al zaragozano Alberto de Megino y Metauten Pérez de Aranda y del Castillo (1759-1820), Conde del Casal ${ }^{19}$, desde 1802 hasta 1808 Cónsul de España en Venecia ${ }^{20}$. Nuestro jesuita le dedica la comedia en agradecimiento a haberle estimulado a traducir el drama y ayudado a publicarlo (pp. V-VIII). Hay que precisar que Megino era un hombre influyente en Venecia, era miembro de prestigiosas academias: Zaragoza, Padua, Verona, Venecia, Berlín, Livorno, Florencia y hasta de la Academia de la Arcadia de Roma con el nombre árcade de Adeneto Eloneo, también había sido condecorado con la Cruz de Carlos III. En la ciudad de la laguna había publicado La Demauxesia ${ }^{21}$ y El aceite ${ }^{22}$, la cual anteriormente (2.VII.1802) no había logrado imprimir en Madrid en la Imprenta Real por falta de fondos. Según su curriculum-vitae ${ }^{23}$ (2.XI.1805) estaba a punto de publicar un opúsculo en italiano sobre El bómito [sic] negro o fiebre amarilla, sus preservativos y curación.

Antonio García demuestra conocer bien el problema de las ediciones españolas de El delincuente honrado al escoger para su traducción la edición príncipe que señalamos a pesar de que en 1803, hubiera salido a la luz otra edición de esta obra ${ }^{24}$. Traduce la obra porque piensa «che il Delinquente sia uno di quelli pochi Drammi, che interessano, e piacciono a tutti» (p. XII). Nuestro traductor declara en las Notizie storiche y Osservazioni del traductore (pp. IX-XVI), que opta por traducir «fedelmente»; traduce, además del texto teatral, la Advertencia de Jovellanos. Precisamente, es de aquí de donde saca las noticias de la génesis de la comedia. En el Apéndice ( $\mathrm{p}$. 128-149) traduce al italiano las dos cartas del traductor francés a Jovellanos (pp. 129$134,148-149$ ) y la respuesta del autor asturiano (pp. 135-147).

La tercera traducción italiana cuyo título es: Il Delinquente onorato la realiza en 1815 Francisco Pomares y se publica en Roma en 1816 en la imprenta de Carlo Mordacchini ${ }^{25}$. En esta comedia no aparece en ningún sitio el nombre de Jovellanos y no

19. Cfr. Francisco Asín Ramírez de Esparza, Don Alberto de Megino, un ilustrado zaragozano en el época de Fernando VII, Zaragoza, Departamento de Historia Contemporánea, Facultad de Filosofía y Letras, 1979. Este ensayo está realizado con los documentos del archivo de la familia Ramírez de Esparza de Zaragoza y algunos del Archivo Histórico Nacional.

20. A.M.A.E., legajo P. 167, expediente 8752.

21. La Denauxesia. Aumentación del pueblo por los medios de procurar que no mueran 50.000 personas que según un cálculo prudencial, y bien formado se pierden anualmente, en las Casas de Espósitos, en los Ospicios y en las Cárceles de España. Es un tratado original de Economía Politica, útil a todo buen patricio, escrito para el bien de la Sociedad por don Alberto de Megino, Cavallero de la Real Orden de Carlos Tercero, Socio de mérito Literario de la de Zaragoza y Cónsul de S. M. C. y de S.M. la Reina Regente de Etruria, Venezia, Antonio Curti hijo de Jac. Impresor y librero, 1805. La obra está dedicada a doña Josefa Juana Nepomucena Alvarez de Faria y Pelliza, Zarzosa y Echevarria.

22. El aceite. Obra escrita por D. Alberto de Megino, Cónsul de su Magestad Católica, Venecia, s.i., 1804. Incluye la traducción española (pp. 45-107) de Lazare Sieuve: Memoria y diario de observaciones y experimentos sobre los medios de precaver las aceitunas de la picadura de los ynsectos. Nuevo método para extraer un aceite más abundante y más fino sirviéndose de un nuevo molino doméstico; y modo de libertarlo de toda rancidez. Escrita en francés y presentada a la Academia de las Ciencias de París en 25 de Enero del 1769 por M. Sieuve de Marsella. La obra está dedicada al primer Secertario de Estado don Pedro de Cevallos.

23. A.H.N., Estado, legajo $3242, n^{\circ} 18$

24. El Delinquente honrado. Comedia en prosa, en cinco actos. Publícala Don Toribio Suárez de Langreo. Octava edición, Madrid, Imprenta de García y Compañía, 1803.

25. Tragi-commedia in prosa il delinquente onorato. Caso accaduto in Segovia, città della Castiglia vecchia nella Spagna l'anno 1783. Tradotta dall'Idioma spagnuolo nell'Italiano dall'Ab. $d$. Francesco Pomares Spagnuolo valenciano in Roma l'anno 1815, Roma, Carlo Mordacchini, 1816. 
va acompañada de una advertencia del traductor; lo que sí señala Pomares en el colofón es que ha utilizado un ejemplar en el que se indica que «L'originale nell'idioma spagnuolo si vende in Barcellona, nell'offficina di Paolo Natale, via del Torrente Giuncheras», dato que sirve para saber que el texto castellano utilizado en la traducción es la edición de Gibért y Tutó que citamos.

Podemos sacar algunos datos de la vida de Francisco Pomares gracias a una instancia, dirigida por éste desde Roma al Rey de España, el 26 de mayo de 1817 en la que solicitaba una pensión o ayuda «para poder susistir» ${ }^{26}$. Francisco Pomares es un ex-jesuita de Elche que debió salir de España de novicio, pues no figura en las relaciones de jesuitas que cobraban pensión; en 1817 era Presbítero y llevaba alrededor de 22 años viviendo en Roma; había publicado un mapa de la Península Ibérica ${ }^{27}$ y quería publicar otro de Europa. Por el momento, no podemos saber los motivos que le impulsaron a traducir esta obra y si Pomares sabía que se trataba de una comedia de Jovellanos.

En 1844 aparece la primera y única traducción de las conocidas hasta ahora hecha por un italiano, el académico «Agiato» Antonio Madernino Gresti, lleva el título: D. Torquato Ramírez ${ }^{28}$. Esta traducción es la entrega 442 de la «Biblioteca ebdomadaria teatrale o scelta raccolta delle più acreditate tragedie, commedie, drammi e farse del teatro italiano, francese, inglese, spagnuolo e tedesco», dirigida en esta época por el conocido autor y actor veneciano Francesco Augusto Bon ${ }^{29}$ (1788-1858). En esta misma colección en la entrega 121, sin indicar el nombre de Moratín, aparece la traducción de El sí de las niñas de D. E. Govean ${ }^{30}$, y en las entregas $136^{31}, 137^{32}$ y $138^{33}$, también sin el nombre del autor español ni el del traductor, sale a la luz la trilogía de los Carlos de Zavala y Zamora, traducida por Francesco Antonio Avelloni, que como veremos, quizá adapta El delincuente honrado. Hay que precisar que en Italia esta tri-

26. A.H.N. Estado, legajo 3.518.

27. Li regni di Spagna e di Portogallo tratti dalle carte che de'due Regni e particolarmente di quello di Spagna ha recentemente pubblicato per ordine e a spese di quella Real Corte il Sig. D. Tommaso López geografo del Re e dalla Gran Carta Marina del Signor Vincenxo Tofigno Caposquadra Assoggettati quindi alle piu moderne osservazioni delineati diligentemente ed incisi da D. Francesco Pomares spagnolo della Provincia di Valenza l'anno 1818. Indice generale alfabetico di tutti i nomi delle città, borghi, paesi, fortezze, monti, filume che si contengono nella gran carta geografica delle Spagne e del Portogallo del Sacerdote Francesco Pomares, aggiuntavi la traduzione spagnuola e latina della dedica e delle descrizioni dei 33 fatti rappresentati in rame, che servono di ornamento alla carta sudetta, s.I., s.i., 1818. En este atlas aparecen también los hechos de armas acaecidos en España desde el año 1808 hasta el de 1814 .

28. D. Torquato Ramirez. Dramma in cinque atti del signor Tovellanos [sic], tradotto dallo spagnuolo da Antonio Madernino Gresti, Accademico Agiato, Milano, Placido Maria Visaj, 1844.

29. Cfr. Vita di Francesco Augusto Bon, preceduta da cenni sulla Commedia italiana nel principio del nostro secolo, per Ignazio Ciampi, Trieste, Tip del Yoyd austriaco, 1866.

30. Il sí delle ragazze. Commedia in tre atti tradotta dall'originale spagntolo, Milano, Placido Maria Visay, 1830. Está dedicado a la señora Desiderata Marucchi nata Castellani.

31. Carlos XII, Re di Svezia all'assedio di Mosca. Parte Prima. Divisa in tre atti, Milano, Placido Maria Visaj, 1830.

32. Carlo XII, Re di Svezia a Pultava. Parte Seconda. Divisa in tre atti, Milano, Placido Maria Visay, 1830. Esta comedia va acompañada de Il Bacio per Cambiale. Commedia in un atto di E. Scribe.

33. Carlo XII, Re di Svezia a Frederiks-Kall. Parte Terza ed ultima. Divisa in tre atti, Milano, Placido Maria Visay, 1830. Esta comedia va acompañada de La Fiera delle Fate. Farsa in un atto. 
logía, según rezan los frontispicios de las ediciones, se atribuye erróneamente a Comella.

La traducción de Madernino Gresti no va acompañada de ninguna advertencia del traductor ni de ninguna noticia sobre el dramaturgo español, aunque algunas comedias de esta colección las tengan. El motivo de que esta versión italiana no sea conocida se debe seguramente a que en el frontispicio y en otros folios de propaganda de la «Biblioteca eddomadaria» el apellido de Jovellanos aparece equivocado: Tovellanos. Este apellido errado viene repetido por Ireneo Sanesi ${ }^{34}$ y así también aparece en los ficheros de muchas bibliotecas.

Francisco Gómez de Terán y Negrete, Cónsul de España en Nápoles, publica en 1848 otra traducción italiana, con el título: Il Delinquente onorato ${ }^{35}$. La obra de Jovellanos va acompañada de las traducciones -también del Cónsul- de La Conjuración de Venecia (1830) de Francisco Martínez de la Rosa y de Don Alvaro o la fuerza del sino (1835) del Duque de Rivas; precedentemente Gómez de Terán también había traducido del Duque de Rivas El moro expósito ${ }^{36}$ (1834) y Mudarra $^{37}$. No hace falta recordar que en esta época Angel de Saavedra era Embajador de España en Nápoles (1844-1850), y don Juan Valera Secretario de esta Embajada; Martínez de la Rosa, también en estos años, fue Embajador en Roma ante la Santa Sede ${ }^{38}$ (1847-1849).

Nos preguntamos si fue idea de Gómez de Terán el haber incluido en este librito la traducción de El delincuente honrado junto a La Conjuración de Venecia y al Don Alvaro; es significativo que el Cónsul utilice y traduzca en la Advertencia el juicio de Martínez de la Rosa sobre El delincuente:

«Il merito principale della composizione di Jovellanos non consiste nell'intrigo e nell'intreccio; ma bensì nel fondo eccellente e nelle solide bellezze che rachiude, degne di ottenergli gli applausi [...] Idee sane di morale e di legislazione espresse con nobiltà e vaghezza, impugnazioni di pregiudizi, funeste passioni naturali e vive, sentimenti virtuosi e teneri, caratteri» (P. 8).

El hecho de que El delincuente, un drama neoclásico, se traduzca en pleno romanticismo se debe a que Jovellanos en su comedia no siempre ha aplicado las reglas neoclásicas, y como ha sido demostrado se puede considerar a Torcuato un héroe tan

34. Cfr. Ireneo Sanesi, La commedia, II, Milano, Vallardi, 1935, pp. 474, 768. Las noticias que conciernen a la literatura española son muy imprecisas y confusas.

35. Il Delinquente onorato. Dramma in 5 atti del Signor D. Gaspare Melchiore de Iovellanos, versione dallo spagnuolo di Francesco Gómez de Terán, en Teatro Moderno Spagnuolo ovvero Collana di produzioni teatrali di Moderni autori spaguoli scelte e tradotte in idioma italiano da Francesco Gómez de Terán, Napoli, Stabilimento tipografico dell'Ancora, 1848. Cada obra tiene numeración independiente.

36. Il Moro esposito o Córdova e Burgos nel secolo decimo. Leggenda in dodici romanze dell'eccellentissimo D. Angelo de Saavedra Duca di Rivas, Ministro Plenipotenziario di S. M. Cattolica la Regin ${ }^{a}$ Isabella II presso la Corte di Napoli. Versione dallo spagnuolo di Francesco Gómez de Terán y Negrete de'Marchesi di Portago con Note, Napoli, Stamperia del Genio tipografico, 1844.

37. Mudarra. Romanzo storico del secolo decimo per Angelo de Saavedra Duca di Rivas. Versione dallo spagnuolo del Cav. Franceso Gómez de Terán. Seconda Edizione con note, Napoli, Tipografia all'insegna del Giglio, 1855.

38. G. di Stefano, «El crepúsculo del liberal: Martínez de la Rosa en Roma en el 48 y el drama Amor de Padre», en Prohemio, I, 2 (1970) pp. 271-278. 
romántico como al Rugiero de La Conjuración de Venecia ${ }^{39}$. Sebold, acertadamente, traza con detalle los numerosos paralelismos que existen entre Don Alvaro y El delincuente honrado ${ }^{\text {to }}$.

No podemos terminar la enumeración de las traducciones italianas de El delincuente sin citar la adaptación de Francesco Antonio Avelloni, alias el Poetino (17561837), que, como acabamos de ver, tradujo y adaptó la trilogía de Zavala y Zamora. Según sospecha Fucilla ${ }^{41}$, Il delinquente onorato de Avelloni podría ser una adaptación del drama de Jovellanos. Según Giulio Natali ${ }^{42}$ se representó en el Teatro dei Fiorentini de Nápoles con gran éxito en 1778, y en 1783 en los de Roma. Entre la vasta producción de Avelloni, en parte manuscrita, no hemos logrado todavía identificar este texto. Moratín, durante su viaje a Italia (1793-1796), no debió de acudir a ninguna representación de esta adaptación, pues no aparece señalada en sus apuntaciones; lo que sí nos dice Inarco es que las obras de Avelloni estaban de moda en los escenarios de Italia, pero califica a Avelloni de «poeta ramplón» y no duda compararle con Comella, Zavala y Moncín ${ }^{43}$.

Antes de empezar a analizar Il Reo per onore de Antonio García López, creemos necesario trazar un breve perfil bio-bibliográfico del traductor. Antonio García es uno de los tantos jesuitas que se habían refugiado en Italia a raíz de la expulsión de España y que Juan Andrés tiene la oportunidad de conocer y tratar en sus viajes a su paso por Ferrara, Bolonia y Roma. Estos jesuitas, según cuenta en una carta a su hermano Carlos:

«daban compasión tantos hombres de talento y de saber, capaces de ilustrar unos las matemáticas, otros otras ciencias naturales, otros las lenguas muertas, otros las buenas letras, viéndolos destituidos de la comodidad y auxilios necesarios para cultivar sus estudios, y sin poder dar a nuestra nación el honor que ciertamente le acarrearían con sus luces si tuvieran mayores proporciones» ${ }^{44}$.

Nuestro jesuita había nacido en Bernuy de Zapardiel ${ }^{45}$, provincia de Ávila, en mayo de 1746; en 1760 entró en el seminario de la provincia de Castilla y en 1767 era estudiante del Colegio Real de Salamanca, provincia de Castilla. Se embarcó el 25 de mayo de 1767 en el Ferrol en el navío «San Genaro». En 1771 residía en Bolonia donde vivió varios años; en 1788 ya se había trasladado a Venecia; aquí le visita

39. Cfr. Michel D. Mc Gaha, «The Romanticism of La conjuración de Venecia», en Kentucky Romance Quarterly, XX (1973), pp. 235-242.

40. Russell P. Sebold, «Jovellanos, dramaturgo romántico», en Anales de Literatura Española, Universidad de Alicante, 4 (1985), pp. 415-437.

4I. J. G. Fucilla, Relaciones, op. cit., p. 200.

42. G. Natali, Il Settecento, Milano, Vallardi, 1960, pp. 925-926. I Sanesi, La commedia, op. cit., II, p. 461, cita estos mismos datos.

43. Cfr. L. Fernández de Moratín, Viage a Italia. Edición crítica de Belén Tejerina, Madrid, Espasa Calpe, 1991 , pp. 448-449.

44. Cartas familiares del Abate D. Juan Andrés a su hermano D. Carlos Andrés, dándole noticia del viage que hizo a varias ciudades de Italia en el año 1785, publicadas por el mismo D. Carlos, I, Madrid, Antonio de Sancha, 1786, pp. 5-6.

45. Cfr. Sommervogel, III, 1892, col. 1201. 
en su viaje a Italia el hermano del Rector del Colegio de España de Bolonia, el helenista Nicolás Rodríguez Lasso ${ }^{46}$.

Según una carta que Juan Zambeccari, Ministro de España en Bolonia, envía a Jerónimo Grimaldi (13.7.1773), el traductor abulense fue detenido en Cento, pueblecito de la provincia de Ferrara, distante pocos kilómetros de Bolonia; trasladado a Bolonia fue encarcelado junto a José Francisco de Isla y Francisco Janausch por «escrituras temerarias» y por «la audacia con que hablaba de los Soberanos y del Papa» y contra el proceso de beatificación de Palafox; además, Antonio García había «traducido al latín y hecho copias del panfleto titulado Vero amico del Papa, aparecido en Roma, el cual fue considerado «un libelo ofensivo a la autoridad suprema de $S u$ Santidad» Clemente XIV ${ }^{47}$.

Entre las obras que actualmente conocemos de Antonio García hay que citar, en primer lugar, la traducción en verso de La Música de Tomás de Iriarte ${ }^{48}$. Dicha traducción realizada con tipos bodonianos, lleva cinco grabados iguales a los de la edición madrileña ${ }^{49}$, todos ellos dibujados por Ferrero y grabados por Fernando Selma $\left(2^{\circ}\right)$, Manuel Salvador Carmona $\left(3^{\circ}\right)$, y Joaquín Ballester $\left(1^{\mathrm{a}}\right.$ y $\left.5^{\circ}\right)$. Esta bella e interesante traducción va acompañada de numerosas notas (pp. I-XXXIV) y de un largo prólogo, en el cual Antonio García impugna algunos puntos de una reseña que hizo Juan Andrés a la edición madrileña. Nicolás Rodríguez Lasso, como acabamos de decir, en la visita que le hizo en Venecia, tuvo la oportunidad de ver la traducción cuando estaba casi terminada. El helenista, dicho sea de paso, confunde el lugar de nacimiento de Antonio García. Tanto Cabezas del Pozo como Bernuy de Zapardiel son pueblos de la provincia de Ávila, y ambos pertenecen al partido judicial de Arévalo. Escribe, pues, N. Rodríguez Lasso:

«Después fuimos con D. Juan de Hacha, exjesuita español, casado con una inglesa, a casa de D. Antonio García, también exjesuita, natural de Cabezas del Pozo, quien nos enseñó la traducción que estaba haciendo del Poema de la Música de Iriarte, en cuya introducción habla con el autor, y con la embajadora y el embajador. Éste le facilitó las láminas que sirvieron para el original en Madrid. Los caracteres eran de Bodoni» ${ }^{50}$.

La traducción de La Música va acompañada de una nota del traductor en la que declara que «ho cercato, che la sua dote principale sia l'esattezza e uno scrupoloso attacamento all'originale per quanto mi è stato permesso dall'indole delle due lingue» ${ }^{51}$. Una novedad que es necesario subrayar es que el jesuita ha optado por poner el punto exclamativo y el interrogativo en la versión italiana también al principio de la frase,

46. E. Giménez López- J. Pradells Nadal, «Los jesuitas expuisos en el viaje a Italia de Nicolás Rodríguez Lasso (1788-1789)», en Revista de Historia Moderna, Anales de la Universidad de Alicante, ${ }^{\circ} 15$ (1996), número dedicado a: Jesuitas en la España del Siglo XVIII, pp. 237-238.

47. A.G.S. Estado, legajo 4737, citado por E. Giménez López- J. Pradells Nadal, «Los jesuitas expulsos», att. cit., pp. $237,248 \mathrm{n}$.

48. La musica poema di D. Tommaso Iriarte tradotto dal Castigliano dall'Abate Antonio Garzia, Venezia, A. Curto Q. Giacomo, 1789.

49. La $1^{\mathbf{a}}$ ed. de La Música (1779) lleva cuatro grabados, la $2^{\mathbf{a}}$ (1784) y la $3^{\mathrm{a}}(1789)$ tienen seis.

50. E. Giménez López- J. Pradells Nadal, «Los jesuitas expulsos», art. cit., p. 238.

51. La introducción no está numerada. 
según costumbre española, no debió cuajar este uso en Italia, pues en las traducciones posteriores no lo vuelve a emplear.

Merece la pena citar también otra obra suya, la traducción en verso del francés al italiano del poema de Jacques Delille (1738-1813) los Jardins ${ }^{52}$ (1782), que es quizá la primera traducción italiana de esta obra. La traducción está dedicada a Carlo Filippo Arrigo de Borbón, Conde d'Artois (pp. 3-6); va acompañada del Avvertimento del editor francés (pp. 7-16) y de numerosas notas a cada uno de los cantos (pp. 163-215) pero no Ileva ninguna nota del traductor italiano. En cambio, en donde explica detalladamente el método que ha seguido en la traducción es en el epitalamio de Claudiano que tradujo para celebrar la boda Sale- Mocenigo ${ }^{53}$. Especifica pues el traductor abulense en la nota Al lettore erudito:

«non è ligia affatto del testo, ovvero grammaticale, ma parafrastica alquanto e libera, onde rischiararlo possibilmente. E`non pertanto bastantemente esatta, o pochissime cose mi sono permeso, che non sieno conformi al testo interamente o da esso senza violentarlo fisicamente... Essendo stato il principale anzi l'unico fine prefissomi in questa traduzione il dare un attestato di omaggio e di riconoscenza alle due famiglie Sale e Mocenigo pel fausto avvenimento di queste unioni» (pp-5-6).

Para celebrar la boda Varanno-Dolfin nuestro traductor también compuso un soneto dedicado al padre del novio ${ }^{54}$. Se sabe además que escribió un poema dedicado a Lunardetto Pesaro ${ }^{55}$. Gracias a una carta de Simón de las Casas ${ }^{56}$, Embajador de Venecia, al Conde de Floridablanca (10.IV.1790) y otra al Duque de la Alcudia (15.VI.1793) sabemos que Antonio García había traducido en endecasílabos al castellano La coltivazione (1546) de Luigi Alamanni (1495-1556) con el fin de dar

«a su patria no sólo un poema acabado que podrá tener bastante influxo en el buen gusto poético, sino también un arte labrantín amena y gustosa, la qual sino será tan magistral, como los tratados que tratan de propósito esta materia, será leída con más gusto y excitará la curiosidad del profesor y del aficionado a buscar en sus fuentes clásicas los verdaderos principios de la primera y más noble de las artes».

García por medio de Simón de las Casas deseaba obtener un permiso para imprimir esta traducción en Italia y más tarde introducirla en España. Alamanni había dedicado muchos de los episodios de su obra a Francisco I de Francia, y García ahora pretende adaptarlos a Carlos IV y dedicárselos a él y a la Real Familia; aspira a que el libro fuera leído en Madrid antes de darlo a la imprenta «para que en ellos no se leyese cosa alguna que no fuese digna de tan sagrados personages». La obra no debió im-

52. I Giardini, Poema del Signor Abate De Lille. Tradotto dal francese dal Sig. Ab. Antonio Garzia, Venezia, Sebastiano Valle, 1792. En la nota a la p. 76 verso 5 (pp. 206-207) «O voi Signore, che del Monarco Ibero» García rinde homenaje a doña Bárbara di Senra, mujer de don Simón de las Casas, Embajador de España en Venecia, por el nacimiento de un hijo, y también a don Luis de las Casas, Gobernador de la Isla de Cuba y Capitán General de Luisiana, mecenas de la obra.

53. Epitalanio di Claudiano nelle nozze di Onorio e Maria, recato in italiano per le nozze Sale Mocenigo dall'abate Antonio Garzia, Padova, Tipografia del Seminario, 1814. Según declara utiliza een la traducción el texto de la edición Elzeviriana publicada en Leiden en 1650.

54. Per le nozze Varanno-Dolfin, Rime, Venezia, 1807.

55. Per la ricuperata salute del Sig. Lunardetto Pesaro... Poemetto storico, Venezia, Antonio Zatta, 1786.

56. A.H.N., Estado, legajo 3239. 
primirse al no tener el visto bueno de la Corte, según la nota del 14 de agosto de 1793: «No se puede juzgar sin ver la obra ni menos aceptarla para S. M.».

El jesuita abulense, guiado por el amor a la patria, desea dar a conocer en Italia el teatro español tal y cómo había sido escrito; de hecho, comenta que una de las razones por las que ha traducido El delincuente «è il voler schivare, ed ovviare in cotal modo l'orribile esempio, e quasi dissi, empio governo, che di questo Dramma potrebbe farsi in Italia, adattandolo forse alle maschere, como 1'hanno provato tanti altri pezzi teatrali spagnuoli, ridotti in questa guisa ad uno stato tale, che non sono più riconoscibili» (p. XII); cita como ejemplo El convidado de piedra y El desdén con el desdén, interpretadas por Arlequín, Pantalón, Colombina y Polichinela.

Il Reo per onore de Antonio García, como dijimos, es una comedia «fedelmente» traducida por un nativo castellano porque en Italia, según manifiesta años antes en la traducción de La Música, en aquellos momentos había poca gente que conociese el español:

«Ma egli è vero altresì, che nel verum preggio, in cui si tiene in Italia la lingua castigliana, la più germana fra tutte le lingue vive del toscano idioma, e tra lo scarso numero di persone, che la intendono, difficilmente si sarebbe trovato chi ponesse mano all'opera con qualche probabilità di riescirne».

A diferencia de otros textos dramáticos de la época en esta traducción no hay ningún cambio en la estructura. El jesuita conserva los cinco actos de la comedia española a pesar de que Jovellanos no haya aplicado las reglas neoclásicas y los actos terminen siempre con el mismo personaje con el que empieza el siguiente, y por tanto los actos funcionan en este drama como si fueran escenas ${ }^{57}$.

Todavía en esta época algunos traductores pensaban que su función era ofrecer a sus lectores un texto que obedecíera a los cánones neoclásicos; en este sentido se pueden interpretar las palabras del traductor francés de El delincuente honrado cuando declara a Jovellanos en la carta que le escribió desde Cádiz el 8 de septiembre de 1777:

«qu'à raison de nos usages particuliers et de nôtre extrème delicatesse j'ai été obligé de changer une grande partie de la pantomime dans le cinquième acte. Le dénouement ne seroit pas assez rapide sur nôtre scène et languiroit trop vôtre pièce est trop bonne pour luy laisser aucun defaut» (p. 125).

La fidelidad de la traducción observada por Antonio García le obliga a respetar el número de escenas ${ }^{58}$, número por cierto considerado demasiado alto para los cánones del teatro neoclásico. Cabe precisar que Jovellanos ha unido siempre las escenas, y por lo tanto nuestro traductor no ha tenido la necesidad de realizar cambios y ha conservado un uso, que en la época, recordemos, era una necesidad más que un ador-

57. El $1^{\circ}$ acto empieza y termina con Torcuato, el $2^{\circ}$ empieza con Simón, Torcuato, Laura y Eugenia y termina con Torcuato, el $3^{\circ}$ acto empieza con Justo, Simón y Torcuato y termina con Justo, el $4^{\circ}$ acto empieza con Justo y el escribano y termina con Justo, el 5 acto empieza con Justo, Torcuato y el escribano y termina con la mayoría de los personajes reunidos en el escenario, como era costumbre en el S. XVIII.

58. El $1^{\circ}$ acto tiene seis escenas, el $2^{\circ}$ catorce, el $3^{\circ}$ y $4^{\circ}$ diez y el $5^{\circ}$ siete. 
no, pues no sólo significaba la continuidad de la acción sino que también contribuía a observar la unidad de lugar.

Es inútil subrayar que los escasos cambios realizados en esta traducción de $E l$ delincuente son de naturaleza lingüística, debidos, muchos de ellos, a un deseo de modernización y de actualización de la comedia para adaptarla al gusto del espectador/lector veneciano; recordemos que el que guste el texto, en la época, es la regla de todas las reglas. García conoce bien las dos lenguas y es consciente de los problemas que puede plantear una traducción hecha por alguien que no es de lengua madre, pero le impulsa a hacerla el amor a la patria, como acabamos de decir. Declara en la nota del traductor al poema de La Música de Iriarte:

«lo non dubito, che questa traduzione fatta da penna italiana sarebbe riuscita più elegante, più nativa, e all'orecchio toscano più gradita. Per quanto si studii una lingua non sua, difficilmente si arriva alla perfezione della terra dei nazionali».

Empecemos por citar un ejemplo de traducción literal en el que ha omitido la acotación «horrorizado» pero trasladando su sentido al texto «oh

«Torq: Si se obstina en callar [Anselmo] sufrirá todo el rigor de la ley... Y tal vez la tortura Horrorizado ¡La tortura! ... ¡Oh nombre odioso! nombre funesto!... ¿Es posible que en un siglo en que se respeta la humanidad, y en que la Filosofía derrama su luz por todas partes, se escuchen aún entre nosotros los gritos de la inocencia oprimida? ... ¿Pero sufriré yo qué por mi causa?... No. El honor me sujeta a la dureza de las leyes, y yo sería digno de ella, si le expusiese por evitarla» (II, 14, p. 48).

«Torquato: Se Anselmo si ostina nel tacere, Egli va sottoposto a tutto il rigor delle Leggi... e forse anche alla tortura... Alla tortura! oh! nome horribile! nome odioso! nome funesto! e possibile sia, che in un secolo, nel quale l'umanità sì rispetta, e la filosofia sparge per ogni dove la benefica sua luce, non si ascoltino fra Noi le grida dell'innocenza calpestata ed oppressa?... Ma e soffrirò io, che per causa mia ... Ah! no; l'onore mi sottoppone a tutta la durezza delle leggi, e tutta sopra di me piomberebbe meritamente, se per evitarla , io l'esponese» (II, 14, pp. 53-54).

Es superfluo quizá insistir en la fidelidad de esta traducción, pero merece la pena citar otro ejemplo más de traducción literal, que corresponde a un momento importante de la obra:

«Ans. Es verdad que has muerto al Marqués de Montilla: pero lo hiciste insultado, provocado y precisado a defender tu honor» (I, 3, p. 12).

Ans. «E' vero, che avete ucciso il Marchese di Montiglia; ma l'avete fatto insultato, provocato, e costretto a difendere il proprio onore» (I, 3, p. 15).

Hemos detectado en contadas ocasiones una tendencia a la amplificación, que a veces tiene una función enfática, con el fin de de subrayar y atraer la atención del espectador/lector: «iAy Laura!» (I, 1, p. 1): «Ah! Laura! amata Laura» (I, 1, p. 3); García aunque amplifique el texto respeta siempre el sentido del original castellano tal y como recomienda Capmany ${ }^{59}$ :

59. A. de Capmany y Suris de Montpalau, Arte de traducir el idioma Francés al Castellano 1776. Edición comentada por $\mathrm{M}^{\mathrm{a}} \mathrm{C}$. Fernández Díaz, Universidad de Santiago de Compostela, 1987. 
«Ah! la imagen de mi esposa ofendida, y los remordimientos de mi conciencia me afligirán en todas partes» (I, 6, p. 25).

«Ah! che l'immagine, la bella ma terribile immagine della mia Sposa offesa, ed i rimorsi laceratori della mia coscienza mi affliggeranno, m'inseguiranno in ogni luogo il più rimoto» $(\mathrm{I}, 6, \mathrm{p} .30)$.

Amplifica también la referencia a Carlos III que indulta de la pena de muerte a Torcuato atribuyéndole virtudes características de un Rey «illuminato», que se corresponde con la imagen que se tenía de este Rey en Europa: «Ah! que Monarca tan piadoso!» (V, 7, p. 115): «Ah! qual Monarca pietoso, umano, benefico!» ( V, 7, p. 124).

Citemos, además, otro ejemplo en el que al amplificar el texto castellano pone en evidencia el honor de Laura, en el que se nota una doble amplificación: una relativa al verbo «no puedes olvidar»: «dimenticare non potete, non dovete sorpassare» $y$ la otra en la que el simple pronombre «te» se transforma en onore y amore «te ha hecho»: «fatti all'onor vostro al vostro amore»:

«Sim. y tú misma no puedes olvidar los agravios que te ha hecho» (III, 6, p. 61).

«Sim. Voi medesima dimenticare non potete, non dovete sorpassare tanti torti in uno fatti all'onor vostro al vostro amore» (III, 6, p. 67).

Esta traducción, al no ser hermeneútica, está estrechamente unida al texto de Jovellanos, por lo que nuestro jesuita respeta el orden de la lista de los «interlocutores» que aparece al empezar la comedia y la traduce tal y como aparece en el texto original, pues posee los datos suficientes para determinar la edad de los personajes y el papel que desempeña cada uno en la obra. Con el fin de adaptar los nombres al público italiano traduce los que se pueden traducir: D. Justo de Lara: D. Giusto di Lara; D. Simón de Escobedo: D. Simone di Escovedo; D. Juan: D. Giovanni; Felipe: Filippo; un Alcayde, dos Centinelas, Tropa y Ministros de Justicia: Un officiale, Capo della polizia, due sentinelle, truppe, e Ministri di giustizia, sbirraglia». Hay que subrayar que para hacer más verosímil el drama ha añadido de su cosecha 'sbirraglia', 'cuadriIla de esbirros' que están presentes al final de la obra. Permanecen invariables: Doña Laura, Torquato Ramírez, D. Anselmo, D. Claudio, Eugenia. De los nombres que aparecen citados en el texto conserva: el Marqués de la Fuente ${ }^{60}$ y Flora Ramírez, tía de Torcuato ${ }^{61}$. Italianiza 'Marqués de Montilla': 'Montiglia' y traduce 'Vicente' (II, 2, p. 30) con una forma dialectal napolitana 'Vicenzo' (II, 2, p. 35). Como «traducir es siempre interpretar ${ }^{62}$, es interesante subrayar en este sentido la adaptación italiana que hace del apellido del Ministro Garroso, (II, 2, p. 29) por Grifagno, (II, 2, p. 34) que utilizado como adjetivo connota un hombre cuya cara tiene una nariz que recuerda el pico de la lechuza o del buho.

La unidad de lugar aparece señalada en el original español: «La scena se supone en el Alcazar de Segovia», él traduce literalmente la frase, y guiado por la verosimili-

60. 1, 3: texto español p. 8, italiano p. 11.

61. I, 3: texto español p. 13, italiano p. 17.

62. G. Folena, Volgarizzare e tradurre, Torino, Einaudi, 1991, p. X. 
tud, precisa que aquí viven las autoridades: «La Scena si suppone nella Fortezza di Segovia abitazione degli Intendenti, o Pubblici Governatori» (p. 2).

Como la preocupación del traductor es que el texto guste en la Italia para la que traduce, no tiene más remedio que modificar la obra según las usanzas del teatro italiano: suprime a veces en algunos pasajes las referencias religiosas caracteristícas de muchas obras del teatro español contribuyendo a simple vista a la laicización de la comedia, así por ejemplo «iSanto Dios» (IV, 10, p. 94) se convierte en «Giusto Cielo» (IV, 10, p. 102) y Jesús! (IV, 6, p. 57) en Povero me! (IV, 6, p. 63); la referencia a la tía de Torquato: «Dios la tenga en descanso» (III, 2, p. 52) se elimina, así como también «Jesús! Jesús!» (I, 9, p. 42); como el ir a misa no estaba de moda en la Venecia para la que interpreta García «Fel. Dixo que iba a Misa, y volvía al instante» (I, 4, p. 17), se transforma en «Filip. Disse, che andava fuori di casa, e che tornava subito» (I, 4, p. 21). Cambios semejantes los realiza Pietro Napoli Signorelli en 1805 cuando traduce El viejo y la niña de Moratín ${ }^{63}$.

De este tipo hay un ejemplo más que merece la pena citar, en el que ha sustituido acertadamente la alusión bíblica a Barrabás por el sustantivo «scelleragine»: p. 46).

«Sim. reos he visto yo que parecían unos santos y eran peores que Barrabás» (II, 12,

«Sim. Ho veduto io più di un Reo, che a guardarlo sembrava un modello di onestà e si scopriva poi il tipo della scelleraggine» (II, 12, p. 52).

Cabe añadir que al no existir en italiano una expresión equivalente a «roncar como un Prior» utiliza un giro diferente que le permite evitar la alusión al mundo religioso:

«quando veo que dando una vuelta al otro lado se echó a roncar como un Prior» (I, 2, p. 3)

«Quando entrai nella sua stanza dormiva profondamente» (I, 2, p. 4).

No obstante es necesario precisar que en la mayoría de las ocasiones Antonio García ha respetado las referencias religiosas del texto y en algunos casos las amplifica, como por ejemplo: « $\mathrm{O}$ justo Dios!» (V, 1, pp. 96-97): «Dio buono! Dio giusto!» (V, I, pp. 96-97), y también: «¡Gran Dios! ¿Así abandonáis al inocente?» (V, II, p. 100): «Dio grande! Dio buono! Così abbandonato l'innocente?» (V, II, p. 108).

De todos modos además queremos citar otros ejemplos para demostrar que en la mayoría de los casos el jesuita traduce fielmente las expresiones religiosas:

«iQuiera el cielo que mis razones sean atendidas!» (V, 2, p. 71).

«Voglia il cielo, che sieno ascoltate lemie ragioni! (V, 2, p. 79).

«Anselmo, asombrado ¿Vos padre suyo? ¡Oh Dios!» (IV, 9, p. 93).

«Ansel. (sorpreso) Voi, suo Padre? Oh! Dio!» (IV, 9, p. 101).

«y a esconderse en el seno del mismo Dios que le ha criado!» (V, 1, p. 99).

«ed a nascondersi e abbissarsi nel seno immenso del Dio steso che lo creò» (V, 1, p. 107).

El deseo de actualizar la traducción lleva a García a dar una visión más moderna de la realidad social, así que él precisa las dos modalidades por las que el hombre puede alcanzar la nobleza:

63. L. Fernández de Moratín, Il vecchio e la giovane, a cura di Belén Tejerina, Napoli, Liguori, 1996, pp. 106-119 
«Torg. Si es un hombre ilustre, un caballero, un militar, ¿de qué le servirá acudir a la justicia» (I, 5, p. 22).

«Torq. Ora s'Egli sia un Uomo illustre o per impiego, o per nascita, un Cavaliere, un Militare, a qual può ricorrere alla Giustizia?» (I, 5, p. 27).

Nuestro traductor, guiado por el deseo de adaptar la versión a su destinatario, se esfuerza por encontrar imágenes equivalentes en italiano o lo más cercanas posibles a las españolas; así por ejemplo en la frase «Hombre, no lo haría ni por una Duquesa» (I, 3, p. 5), se encuentra ante la dificultad de que en España «duquesa» era la dignidad más alta, pero en Venecia no tenía el mismo significado por lo que sustituye la palabra «Duquesa» con un giro para él equivalente: «Non l'avrei fatto nemmeno per la prima Dama della terra» (I, 3, p. 8).

Con las guerras napoleónicas, Francia y todo lo francés estaban de capa caída en Europa y habían dejado de ser modelo de imitación, por lo que Antonio García al actualizar la traducción, se ve obligado a sustituir la referencia precisa al modelo francés con un sustantivo de ámbito general:

«Sim. Todo se reduce a libritos en octavo, y no contentos con hacernos comer y vestir como la gente de extrangía quieren también que estudiemos y sepamos a la Francesa» (I, 5, p. 20).

«Sim. Adesso non si vede altro che tometti in ottavo ben legati e non contenti che mangiamo e vestiamo all'oltremontana vogliamo che impariamo, e sappiamo alla filosofa» (I, 5, pp. 24-25).

Quizá también por motivos de moda y de verosimilitud prefiere reemplazar 'Siberia' por un nombre lejano impreciso:

«Ans. ¿Quieres que te siga? ¿Que vayamos juntos hasta los desiertos de Siberia? Quieres...?»(I, 3, p. 14).

«Ans. Volete, ch' io vi accompagni? Che vi segua sino nei luoghi più inospiti, più deserti? Volete...» (I, 3, p. 18).

Es inútil subrayar que nuestro traductor respeta la unidad de tiempo de El delincuente aunque exceda a los límites permitidos, pues la acción dura unas treinta horas; empieza a las siete de la mañana y termina al día siguiente alrededor de las 11 de la mañana. Recordemos que el tiempo que dura la acción, según los cánones ilustrados, no tenía que sobrepasar el tiempo de la representación, es decir, 263 horas aunque a veces se permitieran algunas horas más. Las alusiones que usa Jovellanos para marcar el transcurso del tiempo García las traduce literalmente, sirvan de ejemplo las siguientes: «Sacando el relox. Las siete y quarto» (I, 2, p. 4): «Tirando fuori l'orlogio. Le sette e un quarto» (I, 2, p. 7); «iTan temprano! Aún no hemos comido» (II, 3, p. 30): «Così presto! abbiamo ancora da pranzare» (II, 3, p. 35); «Señor... la hora ha dado ya» (V, 2, p. 100): «Signore ... l'ora è sonata» (V, 2, p. 108). Hemos encontrado un ejemplo en el que el abulense precisa que Torcuato saldrá de Segovia nada más comer: «Después de comer» (I, 3, p. 15) «Subito dopo aver pranzato (I, 3, p. 19).

Es la verosimilitud lo que obliga al jesuita a acortar el tiempo que Torcuato estaría en Madrid: «Sim. Su marido se va a Madrid por una, o dos semanas» (II, 11, p. 44): «Sim. Suo marito parte per Madrid, dove si tratterrà qualche giorno (II, 11, p. 50 ). 
A pesar de que se representasen con éxito en los teatros italianos pocos años antes las adaptaciones neoclásicas de El Alcalde de Zalamea, realizadas por el jesuita Bernardo García ${ }^{6 t}$ y por el actor y autor teatral Pietro Aldolfati ${ }^{65}$, la comedia calderoniana en esta época estaba desacreditada en Italia y el traductor abulense se ve obligado a sustituir en su versión la concreta alusión a Calderón con 'Commedia':

«Sim. ¡Bueno! ¡lindo! no lo dixeran mejor dos amantes de Calderón» (II, 1, p. 28).

«Sim. Bravi! pulito! Non direbbero meglio due Amorosi di Commedia» (II, 1, p. 33).

Es necesario hacer hincapié en que nuestro jesuita no es un hombre de teatro, es un traductor y no siente la necesidad de traducir al italiano todas las precisas acotaciones escénicas en las que se indican los movimientos o expresiones de los personajes, ni tampoco crear otras nuevas necesarias, por ejemplo, para marcar el transcurso de las horas nocturnas y del amanecer, por lo que esta traducción hay que considerarla un texto para ser leído más que para ser representado ${ }^{66}$. Suprime, pues, García muchas de estas acotaciones: «Laura sobresaltada» (II, 5, p. 35), «Torquato con despecho» (II, 5, p. 36), «Torquato con notable admiración y susto» (II, 6, p. 38), «Simón desde la puerta» (II, 9, p. 42) «Horrorizado» (II, 14, p. 48) «Laura mirándole con horror» (V, 5, p. 105), «Justo, tomando el pliego» (III, 9, p. 67), «Llamando a los centinelas» (IV, 2, p. 72), «Laura entra en la escena corriendo desgreñada y llorosa y su padre deteniéndola» (V, 5, p. 104), «Justo con seriedad» (IV, 6, p. 86).

Por el contrario, conserva y traduce literalmente otras muchas acotaciones como por ejemplo: «Torquato nada le risponde» (I, 2, p. 3): «Torquato niente risponde» (I, 2, p. 6); «Anda por el cuarto poniendo en orden los muebles, y recogiendo alguna ropa de su amo que habrá sobre ellos» (I, 2, p. 4): «Gira per la camera assettando i mobili, e raccogliendo qualche capo di roba del Padrone, che vi sarà sopra» (I, 2, p. 6); «Dándose una palmada en la frente» (I, 3, p. 7): «Battendosi il fronte colla mano» (I, 3, p. 10).

Hay que subrayar que en algún momento el jesuita prefiere sintetizar en vez de suprimir la acotación. Así «Los centinelas se retiran, y Torquato se irá acercando poco a poco a una de las sillas donde se sienta» (IV, 3, p. 73) se convierte en «Torquato pian piano si avvicina ad una sedia e siede» (IV, 3, p. 81). Queremos citar un ejemplo más en el que el traductor explica con más detalle la acción de la acotación, aunque no sea imprescindible para la comprensión del texto: «Vuelve a sentarse, toma un libro, empieza a leer y le dexa al punto» (I, 1, p. 2) que interpreta: «Torna a sedere, prende un libro, comincia a leggere, e subito lo chuide, e lo depone» (I, 1, p. 4).

Recordemos que el aparte sirve para dar a conocer al espectador sentimientos que el personaje no puede expresar en voz alta. Jovellanos utiliza unos veinte, pero casi ninguno está marcado debidamente en el texto y además no todos son cortos, como recomiendan los teóricos dramáticos, que tiene que estar formado por medio ver-

64. Belén Tejerina, «El alcalde de Zalamea de Calderón y la adaptación italiana de Bernardo García: Gonzalo della Riviera ossia il Giludice del propio onore», en curso de publicación en el homenaje que la Universidad de Nápoles ofrece al profesor Mario Di Pinto.

65. Belén Tejerina, «El Alcalde de Zalamea de Pietro Andolfati: Una traducción postrevolucionaria y neoclásica», en Tradurre riscrivere mettere in scena, a cura di Maria Grazia Profeti, Firenze, Alinea, 1996, pp. 211-240.

66. Anne Ubersfeld, Lire le théâtre, Paris, Éditions Sociales, 1978. 
so y no debe sobrepasar el verso, porque dos versos ya no son verosímiles. Empecemos por citar un ejemplo de aparte que Jovellanos ha señalado y el jesuita respeta en su traducción:

«Torquato, aparte ¡Infeliz! Acaso penderá de ese pleyto la subsistencia de su familia» (II, 2, p. 30).

«Torq. (Da se) Infelice! dipendera forse da questa lite la sussistenza della sua famiglia» (II, 2, p. 35).

En otros casos García con tal de ser fiel al texto castellano, opta por no sintetizar los largos apartes, no verosímiles; el ejemplo que citamos a continuación aunque esté recitado desde la puerta no es verosímil y no está señalado como aparte ni por Jovellanos ni por el traductor:

«Escribano, desde la puerta. ¡Con que ternura le habla! Hasta le da el nombre de hijo por consolarle Oh! que exemplo tan digno de imitación y de alabanza!» (IV, 4, p. 81).

«Not. (stando sulla porta) Con quanta tenerezza gli parla! Lo chiama persino col nome di figlio per consolarlo. Oh! qual esempio ben degno d'imitazione e di lode!» (IV, 4, p. 89).

Hemos encontrado también un ejemplo todavía más inverosímil en que don Simón y don Justo recitan el aparte uno después del otro:

«Sim. [...] Yéndose ¡Este D. Justo es un ángel! otros jueces hay tan desabridos, tan $\operatorname{secos} .$. No he visto otro por el termino.

Justo, profundamente pensativo. La fisionomía de D. Torquato ... el tono de su voz... Ah! vanas memorias! Pero es forzoso averiguarlo» (III, 8, p. 67).

«Sim. [...] (nell'atto di andar via) Questo D. Giusto è un angelo di pace. Altri Giudici sono così burberi, così indigesti... Non ho veduto mai il compagno.

Giusto (pensieroso assai) La fisionomia di D. Torquato... il tuono della sua voce... Ah! illusioni... memorie vane e funeste... ma bisogna indagarlo, e secondare le mie inquietudini» (III, 8, p. 74).

Este tipo de apartes nos confirman que Jovellanos no siempre ha aplicado las reglas neoclásicas en su drama:

«Laura mirando a Torquato. Al fin nos han dexado solos: Veamos lo que dice.

Torquato la mira, levanta los ojos al cielo y suspira. Laura ¡Qué afligido está! no me atrevo a preguntarle... Pero es preciso salir de tantas dudas» (II, 5, p. 32).

«Laura. (Guardando Torq.) Finalmente ci hanno lasciato soli; sentiremo quel che dice.

Torquato la guarda, alza gli occhj al cielo, e sospira. Come è Egli afflitto! Non ho coraggio di domandargli... ma bisogna una volta sortire di tanta ambascia» (II, 5, p. 37).

Por el contrario existen también una serie de apartes cortos y, por lo tanto verosímiles, no señalados por Jovellanos mientras que García lo hace en su obra:

«Fel. Muy bien, señor; Que mal humor tiene!» (I, 4, p. 17).

«Filip. Sarà fatto, si Signore. Come è torbido! (Da se) (I, 4, p. 22).

«Torq. ¡Ah! ¡Como podré dexarla!» (II. 1, p. 29).

«Torg. (Da se) Ah! como potrò distaccarmi!» (II, 1, p. 34).

«Fel. Jamás le vi tan impertinente» (II, 12, p. 45). 
«Fel. Non l'ho mai trovato così bisbetico (da se)» (II, 12, p. 50).

No podemos terminar sin poner de relieve los recursos a los que ha acudido nuestro traductor cuando se ha encontrado frente a frases hechas o modismos españoles que no tienen una correspondencia exacta en italiano. Según acabamos de decir, evita también traducir al italiano 'gracias a Dios' con 'grazie a Dio', registrado por Tommaseo-Bellini ${ }^{67}$, que él sustituye por 'finalmente'; se escapa por la tangente al traducir la frase hecha 'dejarle a uno con los huesos en punta' seguramente por no encontrar un modismo correspondiente en el italiano común: «y gracias a Dios le dexo ya con los huesos en punta» (I, 2, p. 3) «e finalmente 1'ho lasciato in punto ed in stato di venire» $(\mathrm{I}, 2, \mathrm{p} .5)$.

Al haber optado por no traducir literalmente «Quando entré en su quarto estaba dormido como un tronco» ( $\mathrm{I}, 2, \mathrm{p}, 2)$ traducido con «Che girando il fianco comincia di nuovo a ronsare più ancora di prima» $(I, 2, \mathrm{p}, 5)$ le resta expresividad a la frase mientras que hubiera podido utilizar expresiones como: 'un ghiro', 'un tasso', 'una marmotta', 'un masso', todas ellas registradas por Tommaseo-Bellini. Traduce con acierto «Estoy aturdido» (II, 9, p. 42) con «Sono restato di sasso» (II, 9, p. 47) y también nos parece acertada la traducción de «le dirá quantas son cinco» (II, 9, p. 42) con «gli saprà stringere i panni addosso» (II, 9, p. 48), también registrado por TommaseoBellini.

Como no existe en italiano un término que corresponda a 'calaberón' «El marqués era un calaberón de quatro suelas» (III, 2, p. 51), el jesuita opta por utilizar tres adjetivos para reforzar la imagen: «Il Marchese era uno stordito, uno sventato, un traviato di prima sfera» (III, 2, p. 57); mientras que hubiera podido traducir con «scavezzacollo di sette cotte» según documenta Tommaseo-Bellini.

Antonio García con el fin de dar en la versión la idea del tiempo transcurrido «que hubo de volver de su profundo letargo, y me dixo que venía corriendo ( $\mathrm{I}, 2, \mathrm{p}$. 2) intraducible literalmente en italiano, opta por amplificar el texto: «e sonnacchioso ancora, e fregandosi gli occhi mi disse che veniva subito» (I, 2, p. 5).

No ha logrado conservar la plasticidad de. 'desembuchar' que traduce con 'dire': «Par diez él será muy tonto en no desembuchar quanto ha visto» (I, 2, p. 4): «Sarà ben buono a non dire quanto Egli sa» (I, 2, p. 6); hay que subrayar que ha omitido traducir 'Par diez' que en italiano podría se 'Per Bacco' registrado por TommaseoBellini.

También conserva el sentido y la forma metafórica, aunque haya pasado del ámbito vegetal al mineral en la traducción de

«Sim. Al fin, si me lo hubiera dicho yo no soy ningún roble» (III, 7, p. 63)

«Sim. Finalmente, se si fosse confidato con me, non sono un marmo, un macigno» (III, 7, p. 70).

Hemos encontrado una interferencia española al traducir 'novela' con 'novella' en lugar de con 'romanzo' documentado por Tómmaseo-Bellini, pero bien pudiera ser una decisión personal por parecerle la historia no suficientemente amplia como para considerarla una novela, y prefiere utilizar en la traducción el sentido de cuento

67. N. Tommaseo, B, Bellini, Dizionario della lingua italiana, 7 vols., Torino, L'Unione Tipografica, 1865-1879. 
«Sim. Señores, quanto pasa parece una novela» $(\mathrm{V}, 6, \mathrm{p} .112) \longrightarrow$ «Signori, tutto ciò che avviene mi sembra una novella» (V, 6, p. 120).

Esta traducción es una traducción muy pensada, basada en un estudio linguístico refinado por una persona que conoce perfectamente las dos lenguas; va dirigida, no a unos espectadores sino a un público de lectores aunque esta versión muy bien hubiera podido ponerse en escena que es el momento en el que el texto teatral alcanza toda su potencialidad. 